Thorax (1971), 26, 288.

\title{
Breath sounds
}

PAUL FORGACS, A. R. NATHOO, and H. D. RICHARDSON Regional Respiratory Laboratory, Brook General Hospital, Shooter's Hill Road, Woolwich, London, S.E.18

Breathing is silent in health but audible at a distance in chronic bronchitis and asthma. This clinical observation was tested by measurements of the intensity of the inspiratory breath sounds at the mouth at flow rates up to $60 \mathrm{l} / \mathrm{min}$. There was a higher rate of increase in the intensity of the sound for equal increments in flow rate in these two diseases than in healthy subjects. Bronchodilator drugs reduced the intensity of abnormally loud inspiratory sounds.

The noise is generated by turbulent flow of air in the upper respiratory tract, the trachea, and the central bronchi. Reduction of bronchial calibre increases flow velocity and intensifies turbulence. The intensity of the inspiratory sound in chronic bronchitis and asthma reflects calibre changes in the trachea, the principal bronchi, and their lobar and segmental branches.

An inverse correlation exists between the intensity of the inspiratory sound, the forced expiratory volume in one second, and the peak expiratory flow rate in chronic bronchitis and asthma, but not in primary emphysema. Discrepancies between sound, airway resistance, and forced expiratory measurements may indicate the site and mechanism of airway obstruction in individual patients.

The sound of inspiration heard with the unaided ear close to the patient's mouth is an important clinical sign. Noisy inspiration is common in chronic bronchitis and asthma, and the degree of narrowing of the central bronchi can be inferred from the loudness of the noise. Silent inspiration in the presence of severe expiratory obstruction is a sign of primary emphysema.

The breathing of a healthy subject appears to be silent to an observer standing close by. In chronic bronchitis and asthma the breath sounds are often so loud that they can be heard across the room. The clinical significance of noisy breathing has not received the attention it deserves. Laennec (1819) devotes a page to it in De l'Auscultation Médiate and is careful to explain that he means simply loud breathing and not the noise of rattling, whistling or any other adventitious sound. $\mathrm{He}$ noticed its association with dyspnoea and mentions such a patient whose breath sounds could be heard at a distance of 20 paces. He thought that this noise came from the glottis, the pharynx, and the nose. Modern textbooks no longer mention breathing audible at a distance and to most physicians breath sounds have come to mean the noise of respiration heard through the stethoscope.

One reason for the neglect of this clinical sign is that the sound of breathing is still attributed to turbulence at the glottis and is therefore thought to be unrelated to the state of the intrathoracic airways. Another reason is lack of precision in the use of the words stridor, wheezing, and noisy breathing. Stridor and wheezing are musical sounds, while the sound of breathing is a featureless noise of no definite pitch. Breath sounds recorded through a microphone close to the mouth contain sound waves of random amplitude (Fig. 1) with an evenly spread frequency distribution between about 200 and 2,000 Hz* (Fig. 2). The

${ }^{*} \mathrm{~Hz}=$ Frequency of oscillation in cycles per second

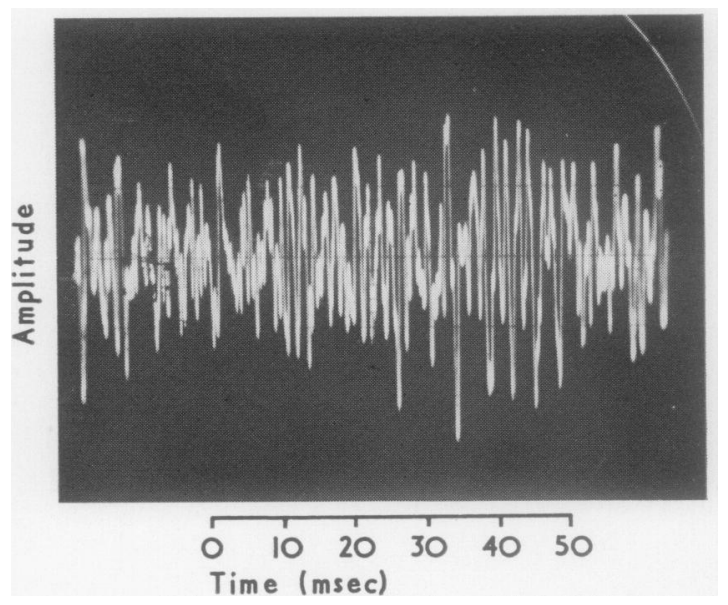

FIG. 1. Inspiratory sound showing random variations in amplitude. 


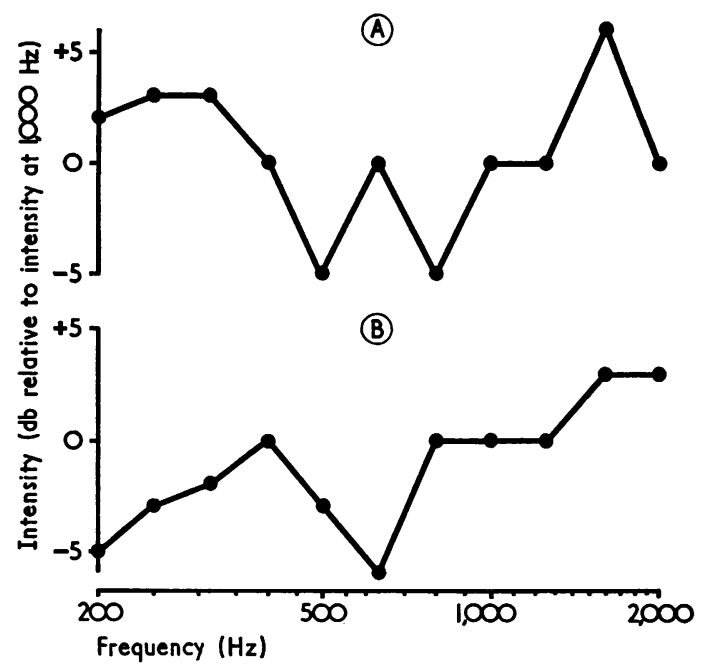

FIG. 2. Spectrogram of the inspiratory sound (A) in a normal subject and (B) in chronic bronchitis.

appropriate term for random oscillations of this type is 'white noise', a term originally suggested by an analogy with white light.

Rapid flow of air in gasping, panting or sighing is noisy even in healthy subjects. Comparative sound measurements must therefore take the instantaneous flow rate into account. In this study the intensity of the breath sounds and the rate of flow were measured simultaneously at the mouth. For technical reasons all observations were confined to the inspiratory white noise, and records contaminated by wheezing were excluded.

\section{METHODS}

The observations were made on adults, breathing naturally through a cardboard cylinder $9 \cdot 2 \mathrm{~cm}$ in length and $2.8 \mathrm{~cm}$ in diameter, held between the teeth and connected to a pneumotachograph head (Mercury Electronics Flow Head Type F.1). A microphone, 2.5 $\mathrm{cm}$ in diameter (Acos 39-1 crystal insert), was set at a distance of $2 \mathrm{~cm}$ facing the open end of the pneumotachograph head (Fig. 3). The pressure changes across the mesh of the pneumotachograph were translated into electrical voltages by a defocusing manometer (Mercury Electronics Type M3-A10 Capsule) with an output of $670 \mathrm{mV}$ for a flow of $501 / \mathrm{min}$. The output of the microphone was $700 \mu \mathrm{V}$ r.m.s. when exposed to

$\dagger \mathrm{mV}=$ millivolt. i.e., $10^{-3}$ volt

$\mu \mathrm{V}=$ microvolt. i.e., $10-6$ volt

r.m.s. = root mean square value of the amplitude of a sine wave $\mathrm{db}=$ decibel. A logarithmic scale of sound measurement based on comparison with an arbitrary standard sound pressure of 0.0002 dynes $/ \mathrm{cm}^{2}$, representing $0 \mathrm{db}$

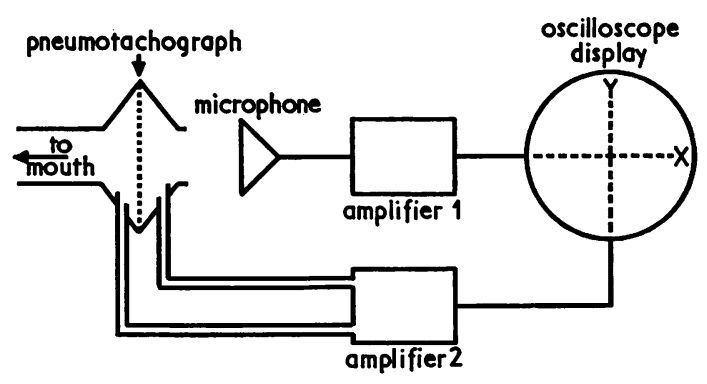

FIG. 3. Instrumentation for simultaneous recording of breath sounds and flow rate at the mouth.

sinusoidal sound waves of $1,000 \mathrm{~Hz}$ at a sound pressure of $74 \mathrm{db}$. + The frequency response of the microphone and the sound amplifying system was within $\pm 3 \mathrm{db}$ of the mean over the range of 300 to $2,000 \mathrm{~Hz}$. The amplified outputs of the microphone and of the pneumotachograph were displayed on the $X$ and $Y$ axis of an oscilloscope fitted with a Polaroid camera, to give deflections of $5 \mathrm{~cm}$ for $250 \mu \mathrm{V}$ and $50 \mathrm{l} / \mathrm{min}$ respectively. In order to exclude transient noises generated during rapid changes of flow, and to avoid errors of measurement due to instrumental lag, pictures were taken only during steady flow. The inspiratory flow rate on inspired volume was displayed on a monitor screen and the film was exposed for $0.1 \mathrm{sec}$ during mid-inspiration when the flow rate was seen to be constant. Each exposure gave a picture of a sample of sound in which all the oscillations during $0.1 \mathrm{sec}$ were superimposed (Fig. 4). The width of the tracing represents the amplitude of the largest oscillation, that is the maximum amplitude of the sound generated at that particular flow rate.

The forced expiratory volume in one second (FEV $)$ was recorded on a Vitalograph spirometer and the peak expiratory flow rate (PEF) was measured with a Wright peak flow meter. The maximum mid-inspiratory flow rate (MMIF) was observed on a flow-volume display by feeding the output of the pneumotachograph on the $X$ axis and the integrated output of the pneumotachograph on the $Y$ axis of the oscilloscope. All volume measurements were corrected to BTPS. Airway resistance $\left(R_{\text {aw }}\right)$ was measured in the body plethysmograph by the method of DuBois, Botelho, and Comroe (1956).

\section{OBSERVATIONS}

NORMAL SUBJECTS At flow rates below 10-20 1/min the inspiratory breath sounds are too faint to appear above the ambient noise. At higher flow rates, up to about $60 \mathrm{l} / \mathrm{min}$, the correlation between the intensity of the inspiratory sound and the flow rate is linear. Observations on 12 normal subjects, each tested on six different occasions, have shown that the intensity 


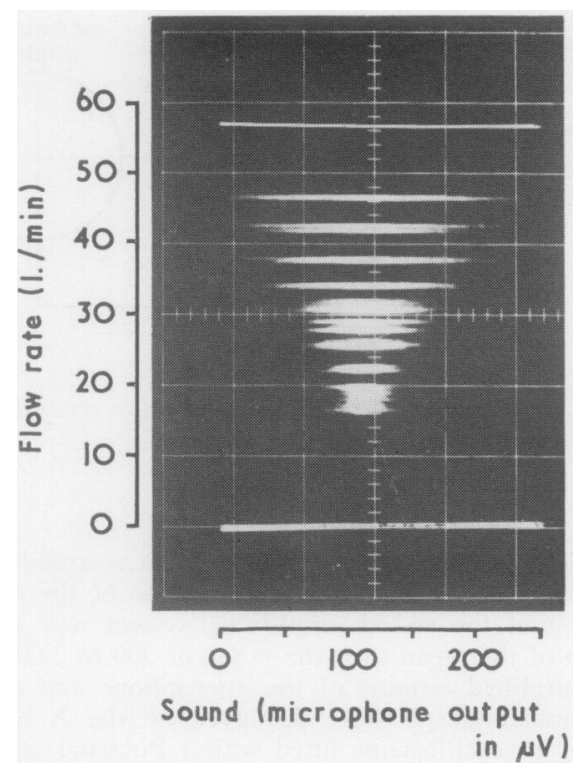

FIG. 4. Composite picture of the maximum amplitude of the inspiratory sound at different flow rates. Each horizontal line represents the superimposed oscillations in a sample of sound during $100 \mathrm{msec}$ at a constant inspiratory flow rate.

of the sound varies little between subjects, or from one day to another in the same subject (Table I).

These observations define the normal inspiratory sound at the mouth in acoustic terms as a white noise of $51 \mathrm{db}$ intensity at a flow rate of $60 \mathrm{l} / \mathrm{min}$. For comparison with abnormally loud breath sounds it is more convenient to define the normal inspiratory sound in electrical terms, as a sound which increases the output of the microphone used in this study by $10 \mu \mathrm{V}$ when the inspiratory flow rate rises by $10 \mathrm{l}$ / min.

CHRONIC BRONCHITIS AND ASTHMA As in normal subjects, in chronic bronchitis and asthma, the inspiratory breath sounds emerge from the ambient noise at a flow rate between 10 and $20 \mathrm{l} / \mathrm{min}$. Above this flow rate the correlation with sound is again linear, but compared with normal subjects the increase in the output of the microphone for corresponding increments in flow rate was usually much greater (Fig. 5). The intensity of abnormally loud breath sounds was calculated by comparing the rate of increase in the output of the microphone with the normal standard, as defined above, and expressing their ratio on a logarithmic scale in decibels above normal. Details of the circulation are as follows:

$P_{1}$ : rate of increase of the output of the microphone per $10 \mathrm{l} / \mathrm{min}$ flow in normal subjects (i.e., $10 \mu \mathrm{V}$ per $10 \mathrm{l} / \mathrm{min}$ )

$P_{2}$ : rate of increase of the output of the microphone per $101 / \mathrm{min}$ flow when exposed to the breath sounds under comparison

$I_{s}$ : intensity of the breath sounds under comparison $I_{s}=20 \log P_{2} / P_{1}$.

(Example: The intensity of breath sounds which increase the output of the microphone by $20 \mu \mathrm{V}$ per $101 / \mathrm{min}$ flow is $20 \log 20 / 10=6 \mathrm{db}$ above normal.)

An assumption implied in this calculation is that the linear increase in the intensity of all normal and abnormal breath sounds starts from the same flow rate. In fact the flow rate at which the breath sounds emerge from the ambient noise varies between subjects from 10 to $201 / \mathrm{min}$. A single figure indicating the difference in intensity between normal and abnormal inspiratory sounds may therefore be accurate only at one particular flow rate. It is, however, a reasonable and convenient approximation for all flow rates within the physiological range.

The mean increase in the intensity of the inspiratory sound in 85 patients ( 58 with chronic bronchitis and 27 with asthma) was $14 \mathrm{db}$ above normal (S.D. 7; range $0-28 \mathrm{db}$ ). Measurements of the inspiratory sound were compared with other laboratory tests of airway obstruction, and the correlation coefficients are set out in Table II. There is a good inverse correlation with the FEV 1 and with the PEF both in chronic bronchitis and in asthma. The correlation between sound intensity and the MMIF was good in chronic bronchitis but not in asthma, while the correlation with $\mathbf{R}_{\mathrm{aw}}$ was poor in both groups of patients. The significance of these differences in relation to the site and mechanism of airway obstruction will be discussed later.

EMPHYSEMA The inverse correlation between the intensity of the inspiratory breath sounds and the

T A B L E I

INSPIRATORY SOUND RELATED TO FLOW RATE IN NORMAL SUBJECTS

\begin{tabular}{|c|c|c|c|c|c|c|c|c|c|c|c|c|c|}
\hline & \multicolumn{12}{|c|}{ Subject No. } & \multirow[b]{2}{*}{$\begin{array}{l}\text { Mean of All } \\
\text { Observations }\end{array}$} \\
\hline & 1 & 2 & 3 & 4 & 5 & 6 & 7 & 8 & 9 & 10 & 11 & 12 & \\
\hline $\mathbf{P}$ & $5 \cdot 8$ & $10 \cdot 0$ & 13.0 & $7 \cdot 2$ & $9 \cdot 8$ & $8 \cdot 7$ & $14 \cdot 1$ & $10 \cdot 7$ & $9 \cdot 7$ & $14 \cdot 5$ & $5 \cdot 1$ & $10 \cdot 8$ & $10 \cdot 1$ \\
\hline S.D. & 1.8 & $2 \cdot 2$ & $6 \cdot 7$ & 0.8 & $3 \cdot 5$ & 4.5 & $5 \cdot 5$ & 3.8 & 3.7 & $2 \cdot 4$ & $1 \cdot 9$ & $2 \cdot 2$ & $4 \cdot 5$ \\
\hline
\end{tabular}

$\mathrm{P}=$ rise in output of microphone in $\mu \mathrm{V}$ per $10 \mathrm{l} / \mathrm{min}$ increase in inspiratory flow (mean of 6 observations) 


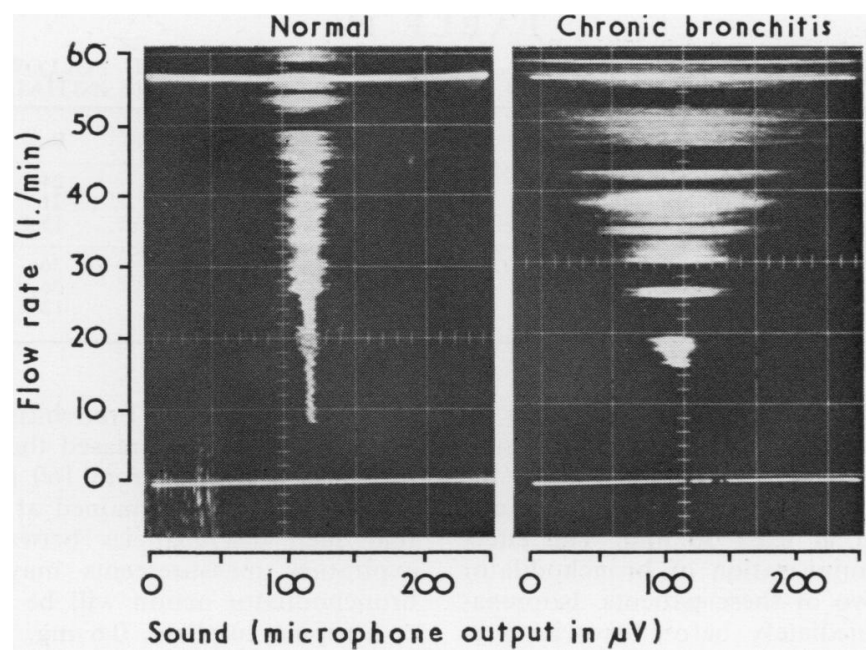

FIG. 5. Rate of increase in the amplitude of the inspiratory sound in a normal subject and in chronic bronchitis.

T A B L E I I

CORRELATION COEFFICIENTS OF INTENSITY OF INSPIRATORY BREATH SOUND WITH FORCED EXPIRATORY VOLUME IN ONE SECOND (FEV) PEAK EXPIRATORY FLOW RATE (PEF), MAXIMUM MID-INSPIRATORY FLOW RATE (MMIF), AND AIRWAY RESISTANCE (Raw)

\begin{tabular}{l|c|c|c|c}
\hline & FEV $_{1}$ & PEF & MMIF & $R_{\text {aw }}$ \\
\cline { 1 - 2 } $\begin{array}{l}\text { Chronic } \\
\text { bronchitis }\end{array}$ & $\begin{array}{l}-0.60 \\
-0.64\end{array}$ & $\begin{array}{l}-0.60 \\
-0.62\end{array}$ & $\begin{array}{l}-0.64 \\
-0.14\end{array}$ & $\begin{array}{r}+0.34 \\
+0.36\end{array}$ \\
\hline
\end{tabular}

FEV 1 and PEF does not apply to primary emphysema. Four patients with the characteristic radiological appearances and functional abnormalities of emphysema who had no previous history of cough or sputum were studied. All four patients had inspiratory breath sounds of normal intensity, in contrast with the severe expiratory obstruction shown by the low FEV 1 and PEF (Table III and Fig. 6).

BRONCHIAL STENOSIS A discrepancy in the opposite sense was observed in three patients, one with cicatricial and two with carcinomatous stenosis of a main bronchus. Their inspiratory breath sounds were louder than predicted from the $\mathrm{FEV}_{1}$, but not sufficiently so to be diagnostic of localized as against widespread bronchial obstruction. Disproportion of this magnitude between sound and FEV 1 was also observed in some patients with chronic bronchitis (Fig. 6).

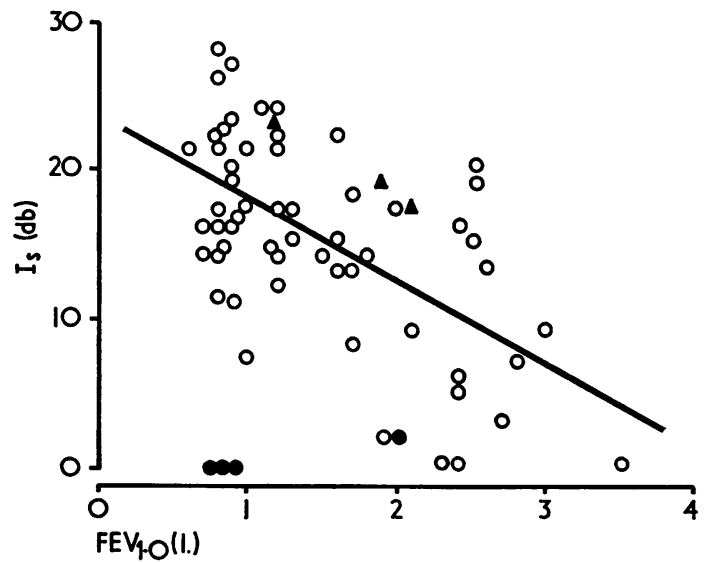

FIG. 6. Scatter diagram of correlation between the intensity of the inspiratory sound and the FEV 1 in chronic bronchitis $\bigcirc$; primary emphysema $\bullet$; and bronchial stenosis $\boldsymbol{\Delta}$.

T A B L E I I I

INSPIRATORY SOUND (Is) IN PRIMARY EMPHYSEMA

\begin{tabular}{|c|c|c|c|c|c|c|}
\hline $\begin{array}{l}\text { Case } \\
\text { No. }\end{array}$ & $\underset{\text { (litres) }}{\mathrm{FEV}_{1}}$ & $\begin{array}{c}\text { PEF } \\
\text { (litres/min) }\end{array}$ & $\underset{(\mathrm{ml} / \mathrm{min} / \mathrm{mmHg})}{\mathrm{T}_{\mathrm{co}}}$ & $\underset{\left(\mathrm{cm} \mathbf{H}_{2} \mathbf{O} / 1 / \mathrm{sec}\right)}{\mathbf{R}_{\mathrm{w}}}$ & $\begin{array}{c}\text { TLC } \\
\text { (litres) }\end{array}$ & $\underset{(\mathrm{db})}{\mathrm{I}_{\mathrm{s}}}$ \\
\hline $\begin{array}{l}1 \\
2 \\
3 \\
4\end{array}$ & $\begin{array}{ll}0.8 & (30) \\
0.8 & (24) \\
2.0 & (57) \\
0.7 & (20)\end{array}$ & $\begin{array}{ll}125 & (25) \\
155 & (28) \\
180 & (32) \\
100 & (16)\end{array}$ & $\begin{aligned} 6 & (24) \\
10 & (43) \\
15 & (49) \\
7 & (22)\end{aligned}$ & $\begin{array}{l}3 \cdot 5 \\
2 \cdot 0 \\
1 \cdot 5 \\
-\end{array}$ & $\begin{array}{ll}6.5 & (100) \\
9.1 & (136) \\
8.9 & (122) \\
8.5 & (130)\end{array}$ & $\begin{array}{l}\mathbf{0} \\
\mathbf{0} \\
\mathbf{2} \\
\mathbf{0}\end{array}$ \\
\hline
\end{tabular}

Figures in brackets represent percentage of the predicted normal value. 
T A B L E I V

CHANGE IN FEV 1 , PEF, AIRWAY RESISTANCE ( $\left.R_{\mathrm{aw}}\right)$ AND SOUND AMPLITUDE FOLLOWING INHALATION OF ISOPRENALINE AEROSOL, EXPRESSED AS A PERCENTAGE OF THE INITIAL VALUE

\begin{tabular}{|c|c|c|c|c|c|}
\hline & & FEV $_{1}$ & PEF & $\mathbf{R}_{\mathbf{a w}}$ & Sound Amplitude \\
\hline Chronic bronchitis & $\begin{array}{l}\text { No. of observations } \\
\text { Mean change }(\%) \\
\text { S.D. }\end{array}$ & $\begin{array}{l}36 \\
15 \\
13 \cdot 5\end{array}$ & $\begin{array}{l}34 \\
26 \\
17 \cdot 9\end{array}$ & $\begin{array}{r}24 \\
-21 \\
15 \cdot 4\end{array}$ & $\begin{array}{r}36 \\
-27 \\
24 \cdot 7\end{array}$ \\
\hline Asthma & $\begin{array}{l}\text { No. of observations } \\
\text { Mean change }(\%) \\
\text { S.D. }\end{array}$ & $\begin{array}{l}37 \\
37 \\
31 \cdot 0\end{array}$ & $\begin{array}{l}37 \\
37 \\
30 \cdot 1\end{array}$ & $\begin{array}{c}36 \\
-36 \\
12 \cdot 0\end{array}$ & $\begin{array}{l}19 \\
-28 \\
16.5\end{array}$ \\
\hline
\end{tabular}

EXERCISE-INDUCED ASTHMA Exercise has no effect on the intensity of the inspiratory sound in normal subjects. In six patients with exercise-induced asthma the intensity of the inspiratory sound rose after exercise and remained high for at least $30 \mathrm{~min}$. The effect of the prophylactic administration of bronchodilator drugs was studied in two of these patients. Isoprenaline aerosol given immediately before exercise prevented the rise in sound intensity, while atropine sulphate, $0.6 \mathrm{mg}$ given by subcutaneous injection one hour before exercise, was ineffective.

BRONCHODILATOR DRUGS The inhalation of isoprenaline aerosol reduced the intensity of the inspiratory sound in chronic bronchitis and in asthma. Observations on 55 patients (36 with chronic bronchitis and 19 with asthma) showed a mean decrease in sound intensity of $4 \mathrm{db}$ (S.D. 3.9; range 0-20 db). A comparison of the proportional changes in $F E V_{1}, P E F$, airway resistance, and sound amplitude produced by isoprenaline aerosol is set out in Table IV. The change in all these measurements was nearly always in the expected direction and was well correlated in magnitude in most patients, but there were exceptions where the $\mathrm{FEV}_{1}$ and PEF improved while the inspiratory sound remained unchanged. For example, in one patient with chronic bronchitis the inhalation of isoprenaline aerosol increased the $\mathrm{FEV}_{1}$ from 1.3 to 1.7 litres and the PEF from 160 to $2301 / \mathrm{min}$ while the inspiratory sound remained at $15 \mathrm{db}$. The possibility that such discrepancies between sound and forced expiratory measurements may indicate the site of bronchodilator action will be discussed later.

Atropine sulphate, $0.6 \mathrm{mg}$, was given by subcutaneous injection to 10 patients with chronic bronchitis. Measurements one hour after the injection showed a fall of between 1 and $9 \mathrm{db}$ in the intensity of the inspiratory sound.

LARYNGECTOMY Sound measurements were made on six patients whose larynx had been resected for cancer some years earlier. They were breathing through a circular or oval stoma, 1-2 $\mathrm{cm}$ in diameter, giving a direct view into the upper $2-3 \mathrm{~cm}$ of the trachea. Sound and flow were measured by the method used on normal subjects, except that the cardboard airway, instead of being held between the teeth, was pressed against the neck just above the jugular notch to make an airtight seal around the stoma.

All these patients had a chronic productive cough, some long before the laryngectomy, others only since the operation. Sputum was seen in the trachea and, in

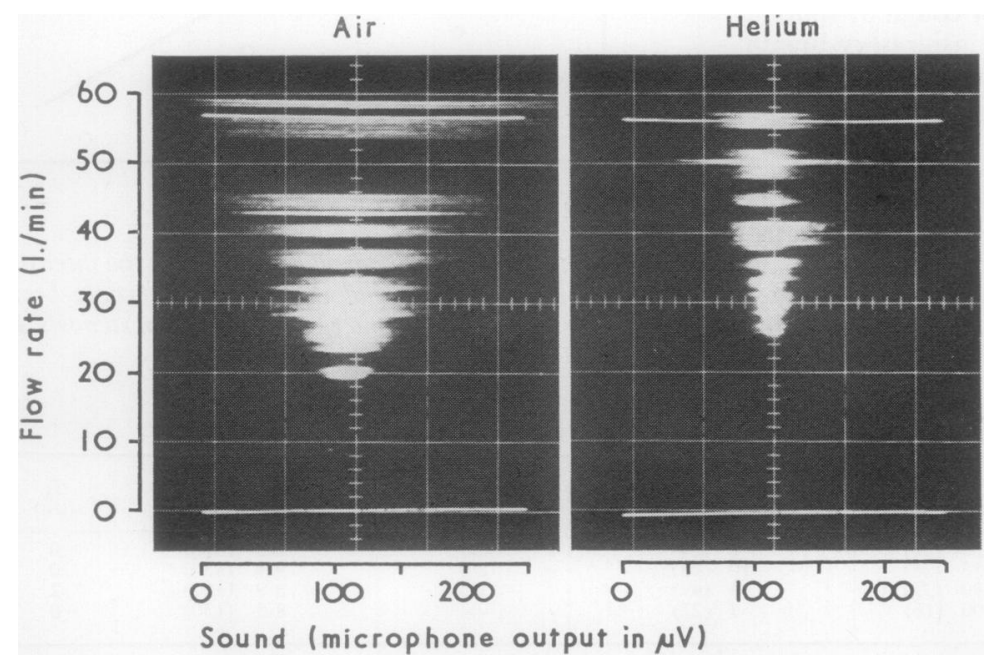

FIG. 7. Decrease in intensity of the inspiratory sound while breathing helium. 
many cases, repeatedly coughed up during the examination. The $F E V_{1}$ and PEF were reduced to about half the predicted value in three patients; in the other three they could not be measured for technical reasons.

The inspiratory sound was above normal in all six patients (mean $16 \mathrm{db}$; range 10-22 db). It is not known what proportion of this noise came from the stoma, but as this orifice was much wider than the normal rima glottidis, and led directly into the trachea without any abrupt change of calibre or direction, its contribution to the noise was thought to be small. The loud inspiratory sounds were probably generated in the intrathoracic airways, by the same mechanism as in chronic bronchitis with intact upper respiratory tracts.

HELIUM The effect of substituting a mixture of $79 \%$ helium and $21 \%$ oxygen for air was observed in seven patients. Four patients belonged to the group with laryngectomy and chronic bronchitis discussed in the previous section. The breath sounds of the other three patients were also noisy, as a result of pneumonectomy, chronic bronchitis, and asthma respectively.

In six patients helium produced a mean fall in the intensity of the inspiratory sound by $8 \mathrm{db}$ (range 2-14 db) (Fig. 7). In one patient the inspiratory sound remained unchanged.

\section{DISCUSSION}

It would be difficult to reconcile these observations with the belief that the noise of inspiration is generated mainly in the upper respiratory tract. This may be so in health, but in chronic bronchitis and asthma it would imply the most improbable assumptions about the shape of the pharynx and the position of the vocal cords. The correlation between the inspiratory sound and the forced expiratory tests, and the change in sound intensity induced by bronchodilator drugs, can be explained only if the loud inspiratory noise is attributed to the infralaryngeal airways. The observation that the inspiratory sound is abnormally loud in chronic bronchitics who had undergone laryngectomy supports this view. It falls short of conclusive proof only because we do not know what proportion of the sound was generated at the stoma. However, as the stoma was often as wide as the trachea itself, it seems likely that the loud inspiratory sounds recorded in these patients came from the intrathoracic airways.

The silencing of the breath sounds by helium proves that the source of the noise is in turbulent gas and not in the solid components of the airways. The difference between these two mechanisms of sound production is shown by the effect of helium on a wheeze compared with that on the respiratory white noise. Wheezing is as loud in helium as in air because the oscillations of the bronchial wall are not affected by the ambient gas, while breath sounds are silenced by helium because flow is less turbulent in gases of low density.

Increased turbulence responsible for noisy breathing may in principle be due to surface irregularities in the airways, abrupt changes in the direction of flow, or to narrowing of the airways resulting in more rapid flow. All these factors may come into play occasionally in disease, but the large fall in sound intensity produced by bronchodilator drugs and the rise following exercise provocation tests show that turbulence in chronic bronchitis and asthma is closely related to the calibre of the airways.

At very low inspiratory flow rates the flow of air in the trachea and bronchi is laminar and presumably silent. At higher flow rates turbulence sets in and some of the kinetic energy of flow is then converted into heat and sound. In engineering problems the transition from laminar to turbulent flow is predictable by the Reynolds number, calculated from the density and viscosity of the gas, the dimensions of the pipe, and the flow velocity.

This prediction is less reliable when applied to a complicated system of branching pipes like the bronchial tree. Even so there is no doubt that beyond the first few generations of the airways flow is always laminar. The flow velocity at any point in the bronchial tree can be calculated from the volume flow measured at the mouth and the total cross-section of all the bronchi of that particular generation. The diameter of individual airways decreases at each division from the lobar bronchi towards the periphery of the lung, but the number of airways in each generation increases exponentially. The large increase in the number of airways conducting air in parallel outweighs the effect of their decreasing calibre. The result is a considerable expansion of the total cross-section of the airways with a corresponding fall in the flow velocity of gas from the central bronchi towards the periphery of the lung. The point of transition from turbulent to laminar flow depends to some extent on the rate of inspiration, but calculations of the Reynolds number in the trachea and the first few generations of the bronchi (Pedley, Schroter, and Sudlow, 1970) shows that in airways of normal dimensions turbulent flow is unlikely beyond the lobar bronchi. Even in chronic bronchitis and asthma, where the central bronchi are believed to be abnormally narrow, the flow velocity is probably not high 
enough to generate turbulence beyond the segmental bronchi.

The intensity of the breath sounds at the mouth therefore reflects the state of that part of the respiratory tract alone where turbulent flow is possible. This includes the upper air passages, the trachea, and the first two or three generations of the bronchi. There is no a priori reason why a measurement of sound intensity, which depends mainly on the inspiratory calibre of the first two or three generations of the bronchi, should show good correlation with any of the usual tests of diffuse airway obstruction, with the possible exception of the maximum mid-inspiratory flow rate. The forced expiratory tests depend upon a complicated interplay of forces which determine at what flow rate and lung volume the large airways collapse and impede expiratory flow. The correlation between the intensity of the inspiratory breath sounds, the $\mathrm{FEV}_{1}$, and the PEF could not have been predicted from first principles. It suggests that the narrowing of the central airways, detected by sound measurements, does not stop short at the segmental bronchi but involves the more peripheral generations of the airways as well. In such circumstances the premature expiratory collapse of the large airways, indicated by the low $\mathrm{FEV}_{1}$ and PEF, could be explained by a steep fall in intrabronchial pressure resulting from high flow resistance in the fourth and succeeding generations of the bronchi.

The intensity of the breath sounds, as measured in this study, and the maximum mid-inspiratory flow rate both depend upon the calibre of the airways at about the same inspiratory lung volume. The good correlation between these two measurements in chronic bronchitis is therefore not unexpected. In asthma, on the other hand, the correlation was poor, mainly because the breath sounds of some patients were louder than predicted from the MMIF. It is known that in asthma there are regional variations in the degree of narrowing of the airways (Bentivoglio et al., 1963). The loud inspiratory sounds in some asthmatics with normal or slightly reduced MMIF may have been due to narrowing of only one or two large bronchi. Observations on patients with stenosis of one of the main bronchi confirm that disproportionately loud breath sounds may be of focal origin.

The lack of correlation between sound and airway resistance suggests that these two measurements reflect the calibre of different sets of bronchi. The body plethysmograph does not indicate the site of high flow resistance, while a loud inspiratory sound is evidence of narrowing of the central bronchi alone. In such circumstances a high airway resistance with faint inspiratory sounds suggests that the main resistance to flow lies beyond the segmental bronchi.

Comparison of the results of different tests of airway obstruction is particularly interesting in primary emphysema. In this disease the intensity of the inspiratory sound is normal, while the FEV $_{1}$ and PEF are often very low. In two patients with this combination of findings the airway resistance was only just above normal. The inference is that there was no reduction of the inspiratory calibre of the airways and that the severe obstruction was due entirely to dynamic expiratory collapse of the large bronchi.

Conclusions on similar lines may be drawn from contradictory results of sound and forced expiratory measurements after the administration of bronchodilator drugs. As a rule the fall in the intensity of the inspiratory noise and the increase of the $\mathrm{FEV}_{1}$ and PEF after inhalation of isoprenaline aerosol go hand in hand. When the inspiratory sound remains unchanged while the forced expiratory measurements improve, as observed in one of our patients, the reason for the discrepancy is either a fixed stenosis of a single central airway or a selective action of the drug on the peripheral bronchi.

In clinical practice it is often sufficient to listen to the noise of inspiration with the unaided ear. Auscultation of the breath sounds is, of course, always included in the clinical examination of the lungs. But the loudness of the breath sounds, as heard through the stethoscope on the chest, depends not only on the intensity of the sound at source but also on its transmission and on the rate of air entry into the underlying territory of the lung (Nairn and Turner-Warwick, 1969; Leblanc, Macklem, and Ross, 1970). In diseases where the calibre of the large airways is of primary interest, it is more informative to listen to the breath sounds at the mouth.

Clinical skill in relating the appropriate loudness of breath sounds at the mouth to the rate and depth of inspiration can be readily acquired. Inspiration is nearly always audible, and often loud in diffuse airway obstruction. Noisy inspiration is a more reliable sign than wheezing of chronic bronchitis and asthma, and its loudness reflects the degree of narrowing of the airways. By contrast, silent inspiration in the presence of severe expiratory obstruction is a valuable clinical sign of primary emphysema.

We are indebted to Mrs. A. G. Cole for the illustrations and technical help with the measurements, and to Mrs. J. A. Lennol for preparing the typescript. 
This study was supported by a research grant from the South East Metropolitan Regional Hospital Board.

\section{REFERENCES}

Bentivoglio, L. G., Beerel, F., Bryan, A. C., Stewart, P. B., Rose, B., and Bates, D. V. (1963). Regional pulmonary function studied with Xenon ${ }^{133}$ in patients with bronchial asthma. J. clin. Invest., 42, 1193.

DuBois, A. B., Botelho, S. Y., and Comroe, J. H. Jr. (1956). A new method for measuring airway resistance in man using a body plethysmograph. J. clin. Invest., 35, 327.
Laennec, R. T. H. (1819). De l'Auscultation Médiate, vol. 1, p. 158. Brosson and Chaudé, Paris.

Leblanc, P., Macklem, P. T., and Ross, W. R. D. (1970). Breath sounds and distribution of pulmonary ventilation. Amer. Rev. resp. Dis., 102, 10.

Nairn, J. R., and Turner-Warwick, M. (1969). Breath sounds in emphysema. Brit. J. Dis. Chest, 63, 29.

Pedley, T. J., Schroter, R. C., and Sudlow, M. F. (1970). The prediction of pressure drop and variation of resistance within the human bronchial airways. Resp. Physiol., 9, 387. 